\title{
3-D Exergy-Based Methods for Improving Energy-Conversion Systems
}

\author{
Tatiana Morosuk*, George Tsatsaronis \\ Institute for Energy Engineering, Technische Universität Berlin, Germany \\ E-mails: morozyuk@iet.tu-berlin.de, tsatsaronis@iet.tu-berlin.de
}

\begin{abstract}
Exergy-based methods (exergetic, exergoeconomic and exergoenvironmental analyses) are powerful tools for developing, evaluating and improving an energy conversion system. Until now, the exergoeconomic and the exergoenvironmental analysis have been conducted independently of each other. This paper presents a way for combining these analyses and for formulating common conclusions for further improvement of an energy conversion system by taking into account simultaneously the minimization of cost and of environmental impact. An academic example consisting of a simple air refrigeration machine, serves as an example for demonstrating the approach.
\end{abstract}

Keywords: Exergetic analysis; exergoeconomic analysis; exergoenvironmental analysis.

\section{Introduction}

Thermodynamic, economic, and environmental-impact analyses are three useful tools used for the evaluation and improvement (optimization) of an energy conversion system. These analyses reveal

(a) the real thermodynamic inefficiencies and the processes that cause them,

(b) the costs associated with equipment and thermodynamic inefficiencies as well as the connection between these two important factors,

(c) the environmental impact associated with equipment and thermodynamic inefficiencies as well as the connection between these two sources of environmental impact, and

(d) possible measures that would improve the efficiency and the cost effectiveness and would reduce the environmental impact of the system being studied.

An exergoeconomic analysis (Bejan et al, 1996; Lazzaretto and Tsatsaronis, 2006; Tsatsaronis, 2008) consists of an exergetic analysis, an economic analysis, and an exergoeconomic evaluation. An exergoenvironmental analysis (Tsatsaronis, 2008; Meyer et al., 2009) consists of an exergetic analysis, a life cycle assessment (LCA) of the environmental impact and an exergoenvironmental evaluation conducted in analogy with the exergoeconomic one.

In the exergoeconomic and exergoenvironmental analyses (which are already known as powerful tools for analyzing, evaluating and improving energy-conversion systems) the economic analysis and the LCA (therefore the exergoeconomic and the exergoenvironmental analysis) are conducted independently of each other. Obviously then the conclusions from these analyses are also obtained independently.

In this paper we try to obtain consistent conclusions on how to improve an energy-conversion system by reducing cost and environmental impact. Note that we do not want to assign cost values to environmental impacts (or vice versa) because of the arbitrariness and uncertainty associated with such procedures. As before, the main assumption is that data obtained from an LCA and from a cost analysis are independent from each other.

\section{Exergy-Based Analyses}

\subsection{Exergetic Analysis}

Using the exergy rates associated with fuel and product (Tsatsaronis, 1984; Bejan et al., 1996; Lazzaretto and Tsatsaronis, 2006), $\dot{E}_{F, k}$ and $\dot{E}_{P, k}$, respectively, the exergetic balance for the $k$-th component is

$\dot{E}_{F, k}=\dot{E}_{P, k}+\dot{E}_{D, k}$

The total exergy destruction within the $k$-th component ( $\dot{E}_{D, k}$ ) can be determined through this balance.

The exergetic efficiency for the $k$-th component is

$\varepsilon_{k}=\frac{\dot{E}_{P, k}}{\dot{E}_{F, k}}=1-\frac{\dot{E}_{D, k}}{\dot{E}_{F, k}}$

Additional variables used in the exergetic analysis can be found in many publications, for example, Bejan et al., 1996; and Lazzaretto and Tsatsaronis, 2006.

\subsection{Exergoeconomic Analysis}

The exergoeconomic analysis is an exergy-based method that identifies and calculates the location, magnitude, causes and costs of thermodynamic inefficiencies in an energy-conversion system. An exergoeconomic analysis is conducted at the component level of a system and reveals (a) the relative cost importance of each component, and (b) options for improving the overall cost effectiveness.

The exergoeconomic model of an energy conversion system (Bejan et al., 1996; Lazzaretto and Tsatsaronis, 2006) consists of cost balances and auxiliary costing equations.

The cost balances are formulated for each system component: 


$$
\dot{C}_{P, k}=\dot{C}_{F, k}+\dot{Z}_{k}
$$

or

$$
c_{P, k} \dot{E}_{P, k}=c_{F, k} \dot{E}_{F, k}+\dot{Z}_{k}
$$

Here $\dot{C}_{P, k}$ and $\dot{C}_{F, k}$ are the cost rates associated with fuel and product, whereas $c_{P, k}$ and $c_{F, k}$ are the corresponding costs per unit of exergy. Finally $\dot{Z}_{k}$ is the sum of cost rates associated with capital investment $(C I)$ as well as operating $\&$ maintenance $(O \& M)$ expenditures for the $k$-th component

$$
\dot{Z}_{k}=\dot{Z}_{k}^{C I}+\dot{Z}_{k}^{O M}
$$

To simplify the discussion, we assumed in the present paper, that the contribution of $\dot{Z}_{k}^{O M}$ remains constant when design changes are made, and, therefore, the changes in the value of $\dot{Z}_{k}$ are associated only with changes in the capital investment cost $\dot{Z}_{k}^{C I}$.

The auxiliary costing equations are based on the $\mathrm{P}$ and $\mathrm{F}$ rules, as they have been finalized by Lazzaretto and Tsatsaronis, 2006.

The following exergoeconomic variables may be used for improving the cost effectiveness of the overall system in an iterative optimization:

- $\quad$ Cost rate associated with the exergy destruction within the $k$-th component

$$
\dot{C}_{D, k}=c_{F, k} \dot{E}_{D, k}
$$

- Total expenses associated with the component, which are the sum $\left(\dot{Z}_{k}^{C I}+\dot{C}_{D, k}\right)$

- Relative cost difference

$$
r_{k}=\frac{c_{P, k}-c_{F, k}}{c_{F, k}}=\frac{1-\varepsilon_{k}}{\varepsilon_{k}}+\frac{\dot{Z}_{k}}{c_{F, k} \cdot \dot{E}_{P, k}}
$$

\section{- $\quad$ Exergoeconomic factor}

$$
f_{k}=\frac{\dot{Z}_{k}^{C I}}{\dot{Z}_{k}^{C I}+\dot{C}_{D, k}}=\frac{\dot{Z}_{k}^{C I}}{\dot{Z}_{k}^{C I}+c_{F, k} \cdot \dot{E}_{D, k}}
$$

\subsection{Exergoenvironmental Analysis}

An exergoenvironmental analysis is an exergy-based method that identifies and calculates the location, magnitude, causes and environmental impact of thermodynamic inefficiencies in an energy conversion system (Tsatsaronis, 2008; Meyer et al., 2009). An exergoenvironmental analysis is also conducted at the component level of a system and identifies (a) the relative importance of each component with respect to environmental impact, and (b) options for reducing the environmental impact associated with the overall system. In an exergoenvironmental analysis, a one-dimensional characterization indicator is obtained using a Life Cycle Assessment (LCA). This indicator is used in a similar way as the cost is used in exergoeconomics. An index (a single number) describes the overall environmental impact associated with system components and exergy carriers. The Eco-indicator 99 (Goedkoop and Spriensma, 2000) is an example of such an index and is used here. It should be emphasized that the evaluation of environmental impacts will always be subjective and associated with uncertainties. However, the information extracted from the exergoenvironmental analysis is very useful, and future work should also focus on reducing the arbitrariness associated with the LCA and the index used in the analysis.

The exergoenvironmental model of an energyconversion system consists of environmental-impact balances and auxiliary environmental-impact equations.

The environmental-impact balances are written for each system component:

$\dot{B}_{P, k}=\dot{B}_{F, k}+\left(\dot{Y}_{k}+\dot{B}_{k}^{P F}\right)$,

or

$b_{P, k} \dot{E}_{P, k}=b_{F, k} \dot{E}_{F, k}+\left(\dot{Y}_{k}+\dot{B}_{k}^{P F}\right)$

Here $\dot{B}_{P, k}$ and $\dot{B}_{F, k}$ are the environmental-impact rates associated with product and fuel respectively, and $b_{P, k}$ and $b_{F, k}$ are the corresponding environmental impacts per unit of exergy for product and fuel. To separately account for pollutant formation within the $k$ th component during system operation, a new variable was introduced $\dot{B}_{k}^{P F}$ (Boyano at al., 2011). This term $\dot{B}_{k}^{P F}$ is zero if no pollutants are formed within a process, i.e. for processes without a chemical reaction (compression, expansion, heat transfer, etc.). For components, where chemical reactions occur (for example, combustion), the rule on how to calculate the value of $\dot{B}_{k}^{P F}$ is described in detail by Boyano at al. (2011).

The auxiliary environmental impact equations are based on the $\mathrm{P}$ and $\mathrm{F}$ rules, which are applied in analogy to exergoeconomics (Tsatsaronis, 2008; Meyer et al., 2009).

The following exergoenvironmental variables may be used for reducing the environmental impact associated with the $k$-th component:

- $\quad$ Environmental-impact rate associated with the exergy destruction within the $k$-th component

$\dot{B}_{D, k}=b_{F, k} \dot{E}_{D, k}$

- $\quad$ Relative environmental impact difference

$r_{b, k}=\frac{b_{P, k}-b_{F, k}}{b_{F, k}}=\frac{1-\varepsilon_{k}}{\varepsilon_{k}}+\frac{\dot{Y}_{k}}{b_{F, k} \cdot \dot{E}_{P, k}}$

- Exergoenvironmental factor

$f_{b, k}=\frac{\dot{Y}_{k}^{C O}}{\dot{Y}_{k}^{C O}+\dot{B}_{D, k}}=\frac{\dot{Y}_{k}^{C O}}{\dot{Y}_{k}^{C O}+b_{F, k} \cdot \dot{E}_{D, k}}$

\section{3D Analysis}

Figure 1 shows some possible dependencies among exergy destruction, capital investment cost and 
construction-of-component-related environmental impact (Tsatsaronis and Morosuk, 2008). The effect of component size is taken into consideration in this figure by relating $\dot{E}_{D, k}, \dot{Z}_{k}^{C I}$ and $\dot{Y}_{k}^{C O}$ to the product exergy rate associated with the same component at the given operation conditions $\left(\dot{E}_{P, k}\right)$.
In Fig.1 single curves are shown for simplicity. In reality each curve should be replaced by a rather wide area representing the fact that for each value of relative exergy destruction $\left(\dot{E}_{D, k} / \dot{E}_{P, k}\right)$, both the $\dot{Z}_{k}^{C I} / \dot{E}_{P, k}$ and $\dot{Y}_{k}^{C O} / \dot{E}_{P, k}$ values can vary within a rather wide range.

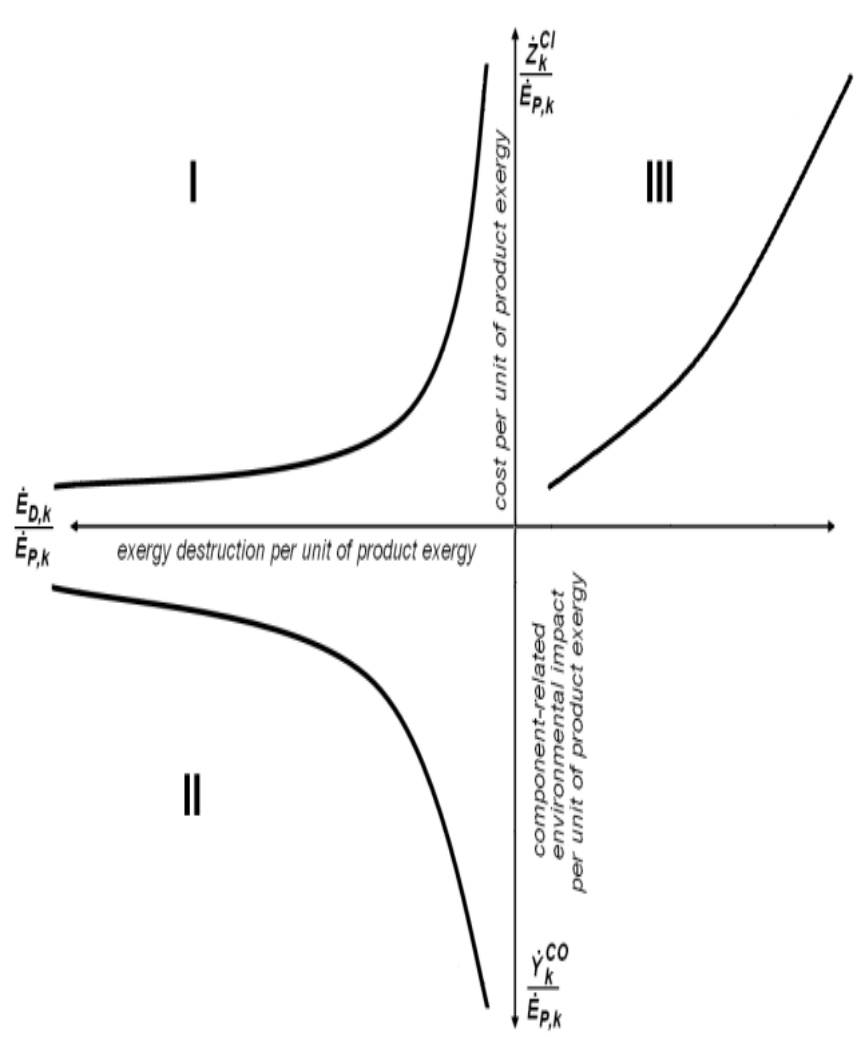

(a)

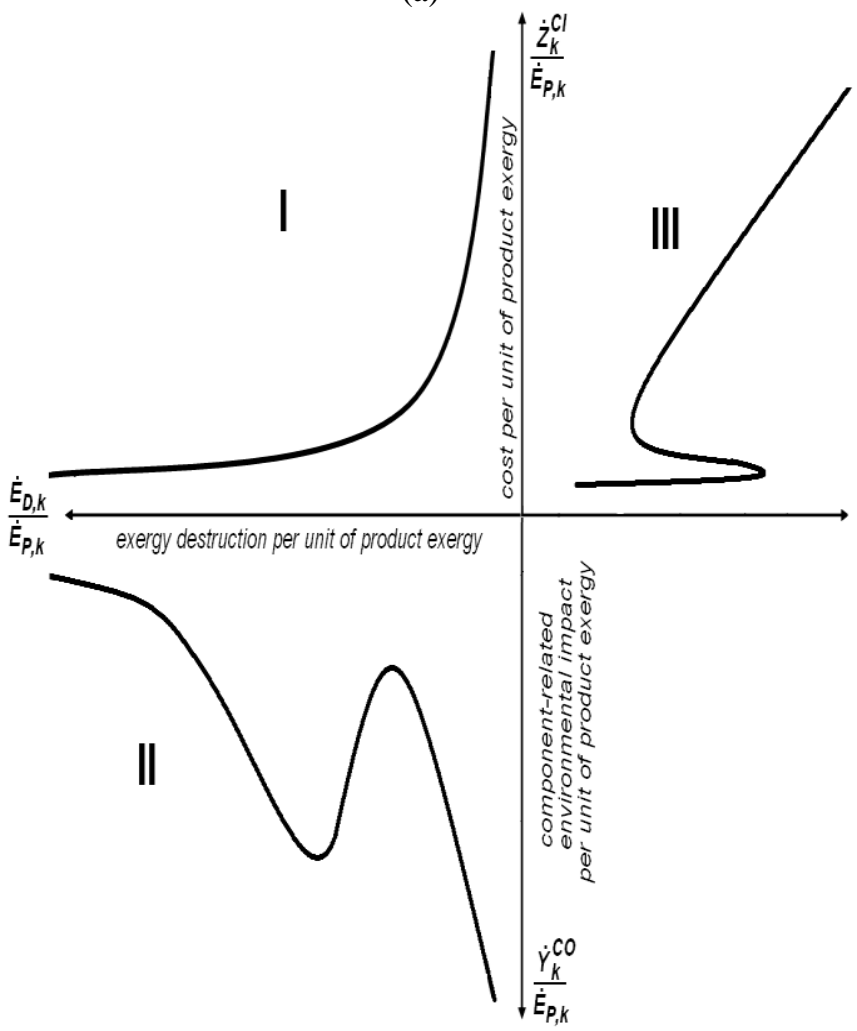

(c)

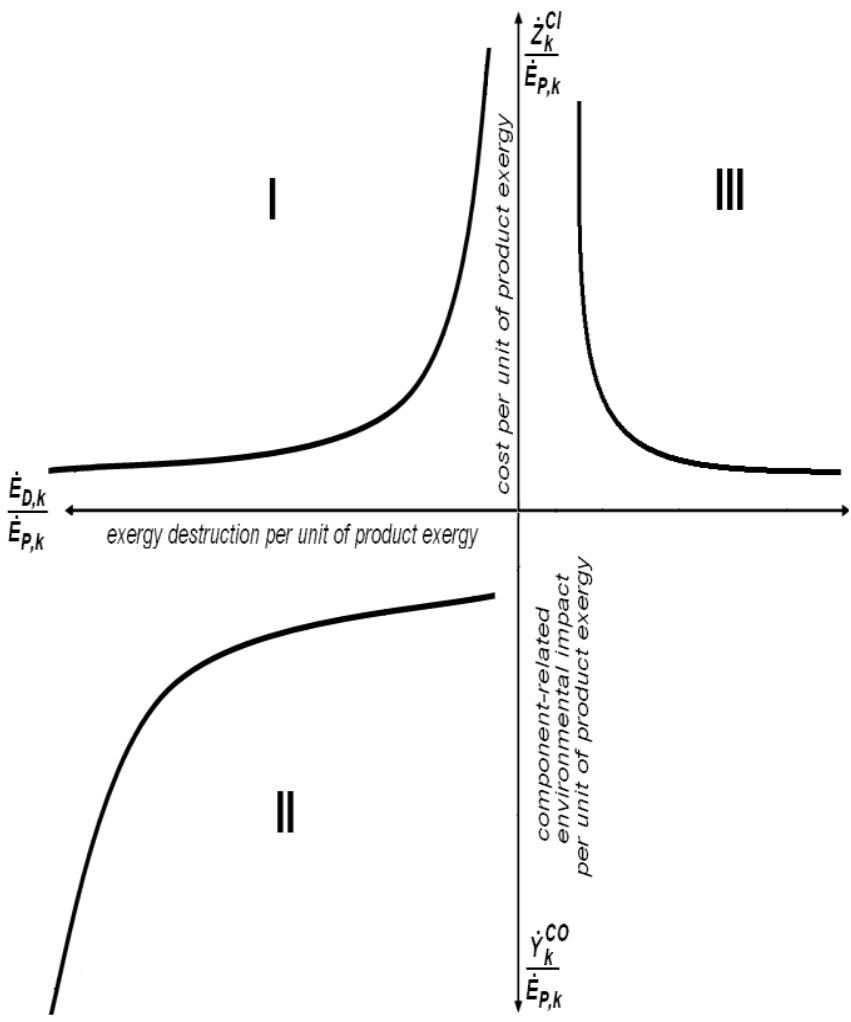

(b)

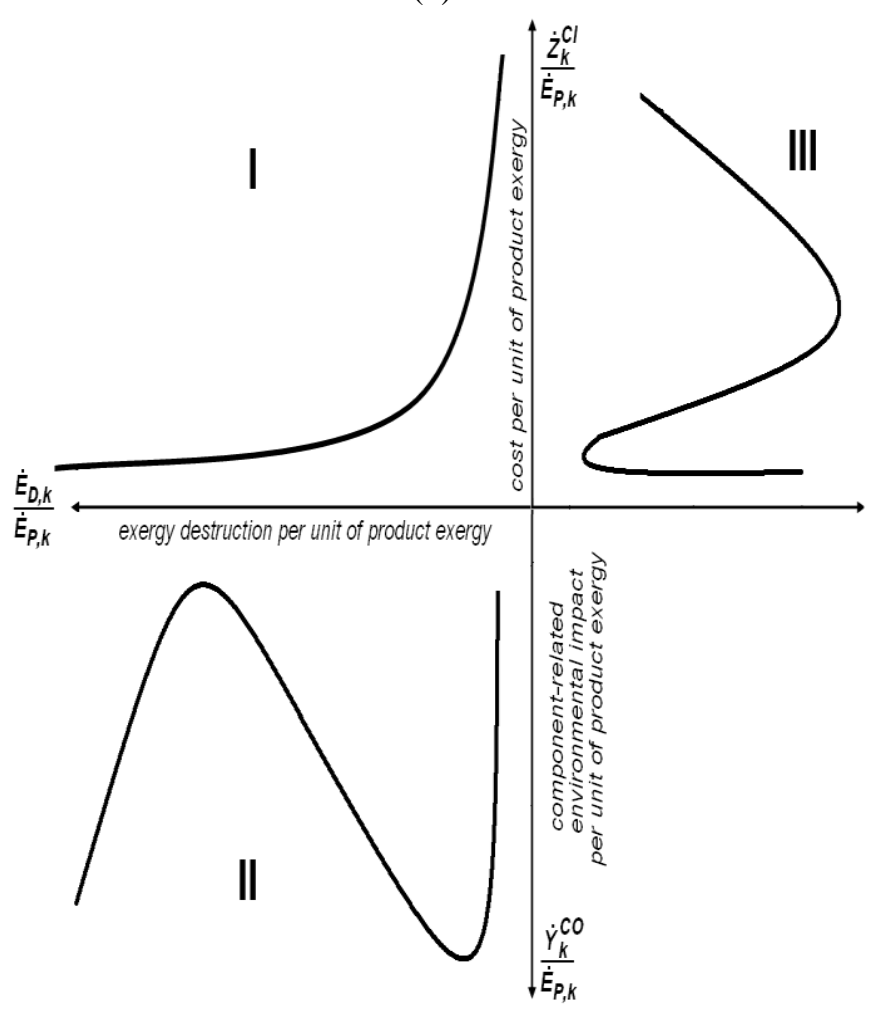

(d)

Figure 1. Expected relationships among capital investment, construction-of-component-related environmental impact and exergy destruction for the $k$-th component of an energy conversion system. 
The values $\dot{Y}_{k}^{C O} / \dot{E}_{P, k}$ shown in the lower left part of each plot (quarter II) in Fig. 1 could have different shapes since some design changes might correspond to entirely different materials and/or manufacturing methods being used for the construction of component $k$, and, thus, to different curves for the environmental impact. Until now the character of this curve has not been studied, therefore the four curves (a-d) shown here in quarters II are just some examples of possible options.

The resulting functions given in the upper right part of each plot (quarter III) are of particular importance for the simultaneous reduction of investment cost and environmental impact.

In this paper, we study the dependencies among three functions: $\dot{E}_{D, k} / \dot{E}_{P, k}, \dot{Z}_{k}^{C I} / \dot{E}_{P, k}$, and $\dot{Y}_{k}^{C O} / \dot{E}_{P, k}$ using a particular academic example (a simple air refrigeration machine).

\section{Study Case}

Figure 2 shows a simple air refrigeration machine that is used as an academic example. The machine consists of a compressor $\left(\mathrm{CM}, \eta_{C M}=0.8\right)$ driven by an expander (EX, $\left.\eta_{E X}=0.8\right)$ and an electrical motor (EM, $\left.\eta_{E M}=0.9\right)$ simultaneously, a heat exchanger (HE) where the working fluid is cooled by water, and a refrigerator $(\mathrm{R})$ where the working fluid is heated by air. The refrigeration capacity of the machine is assumed to be $\dot{Q}_{\text {cold }}=100 \mathrm{~kW}$. The compressor and the expander are turbomachines with a theoretical pressure ratio $p_{3} / p_{1}=5$, the heat exchanger is a fin heat exchanger with an overall heat transfer coefficient of approximately $U_{H E}=0.05 \mathrm{~kW} / \mathrm{m}^{2} \cdot \mathrm{K}$, and the refrigerator is a plate heat exchanger with an overall heat transfer coefficient of approximately $U_{R}=0.01 \mathrm{~kW} / \mathrm{m}^{2} \cdot \mathrm{K}($ Kakac and Liu, 1998).

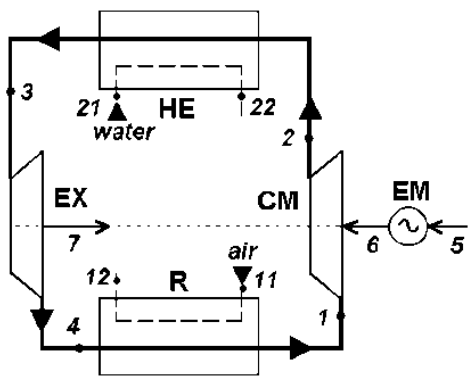

Figure 2. Schematic of a simple air refrigeration machine.
The thermodynamic data obtained from the simulation are given in Table 1. According to the energetic analysis: $\dot{W}_{C M}=776.7 \mathrm{~kW}, \dot{W}_{E X}=373.9$, therefore $\dot{W}_{\text {cycle }}=402.8$ $\mathrm{kW}$ and $\dot{W}_{E M}=447.6 \mathrm{~kW} ; \dot{Q}_{H E}=502.8 \mathrm{~kW}$ with $A_{H E}$ $=235.9 \mathrm{~m}^{2} ; \dot{Q}_{R}=\dot{Q}_{\text {cold }}=100 \mathrm{~kW}$ with $A_{R}=380.5 \mathrm{~m}^{2}$. The coefficient of performance of the air refrigeration machine is $C O P=\frac{\dot{Q}_{\text {cold }}}{\dot{W}_{E M}}=0.25$. Note that the energetic efficiency of an air refrigeration machine $(C O P)$ is very low in general, and the value of $C O P=0.25$ for the machine analyzed here is a realistic one.

\section{Exergy analysis}

The values of exergy for all material streams consist only of physical exergy. The physical exergy is split into thermal and mechanical parts (Morosuk and Tsatsaronis, 2005). These values are given in Table 1 . The definition of the exergy of fuel and exergy of product are given in Table 2 . The results obtained from the exergetic analysis are given in Table 3.

\section{Exergoeconomic analysis}

The estimation of the purchased equipment costs (PEC) associated with the components of the air refrigeration machine for the Base Case has been discussed in detail by Morosuk and Tsatsaronis, 2011a, b. The values of PEC are calculated in $€$ for the year 2010. The cost of electricity is assumed to be $c_{e l}=0.12 € / \mathrm{kWh}$ in the year 2010 .

For the sensitivity analysis we developed the following cost equations (based on data published by Morosuk and Tsatsaronis, 2011a, b) for estimating the PEC as a function of the thermodynamic parameters for the compressor and expander:

\section{- Compressor}

$$
P E C_{C M}=\frac{533.6 \cdot \dot{m}_{c y c l e}}{\eta_{C M}^{U N}-\eta_{C M}}\left(\frac{p_{2}}{p_{1}}\right) \ln \left(\frac{p_{2}}{p_{1}}\right)
$$

- Expander

$$
P E C_{E X}=\frac{1052 \cdot \dot{m}_{\text {cycle }}}{\eta_{E X}^{U N}-\eta_{E X}}\left(\frac{p_{3}}{p_{4}}\right)
$$

Table 1. Thermodynamic data for the air refrigeration machine for base-case operation conditions.

\begin{tabular}{|c|l|r|r|r|r|r|r|r|}
\hline Stream & $\begin{array}{c}\text { Material } \\
\text { stream }\end{array}$ & $\begin{array}{c}\dot{m} \\
{[\mathrm{~kg} / \mathrm{s}]}\end{array}$ & $\begin{array}{c}T \\
{\left[{ }^{\circ} \mathrm{C}\right]}\end{array}$ & $\begin{array}{c}p \\
{[\mathrm{bar}]}\end{array}$ & $\begin{array}{c}h \\
{[\mathrm{~kJ} / \mathrm{kg}]}\end{array}$ & $\begin{array}{c}e^{T} \\
{[\mathrm{~kJ} / \mathrm{kg}]}\end{array}$ & $\begin{array}{c}e^{M} \\
{[\mathrm{~kJ} / \mathrm{kg}]}\end{array}$ & $\begin{array}{c}e \\
{[\mathrm{~kJ} / \mathrm{kg}]}\end{array}$ \\
\hline $\mathbf{1}$ & Air & 4.198 & -30 & 1.00 & 243.4 & 5.82 & 0 & 5.82 \\
\hline $\mathbf{2}$ & Air & 4.198 & 153.6 & 5.25 & 428.4 & 21.97 & 141.90 & 163.87 \\
\hline $\mathbf{3}$ & Air & 4.198 & 35 & 5.00 & 308.6 & 0.15 & 137.70 & 137.85 \\
\hline $\mathbf{4}$ & Air & 4.198 & -53.76 & 1.05 & 219.6 & 12.73 & 4.17 & 16.90 \\
\hline $\mathbf{1 1}$ & Air & 9.968 & -10 & 1.00 & 263.4 & 2.24 & 0 & 2.24 \\
\hline $\mathbf{1 2}$ & Air & 9.968 & -20 & 1.00 & 253.4 & 3.80 & 0 & 3.80 \\
\hline $\mathbf{2 1}$ & Water & 8.015 & 25 & 1.50 & 104.9 & 0 & 0.05 & 0.05 \\
\hline $\mathbf{2 2}$ & Water & 8.015 & 40 & 1.5 & 167.6 & 1.53 & 0.05 & 1.58 \\
\hline
\end{tabular}




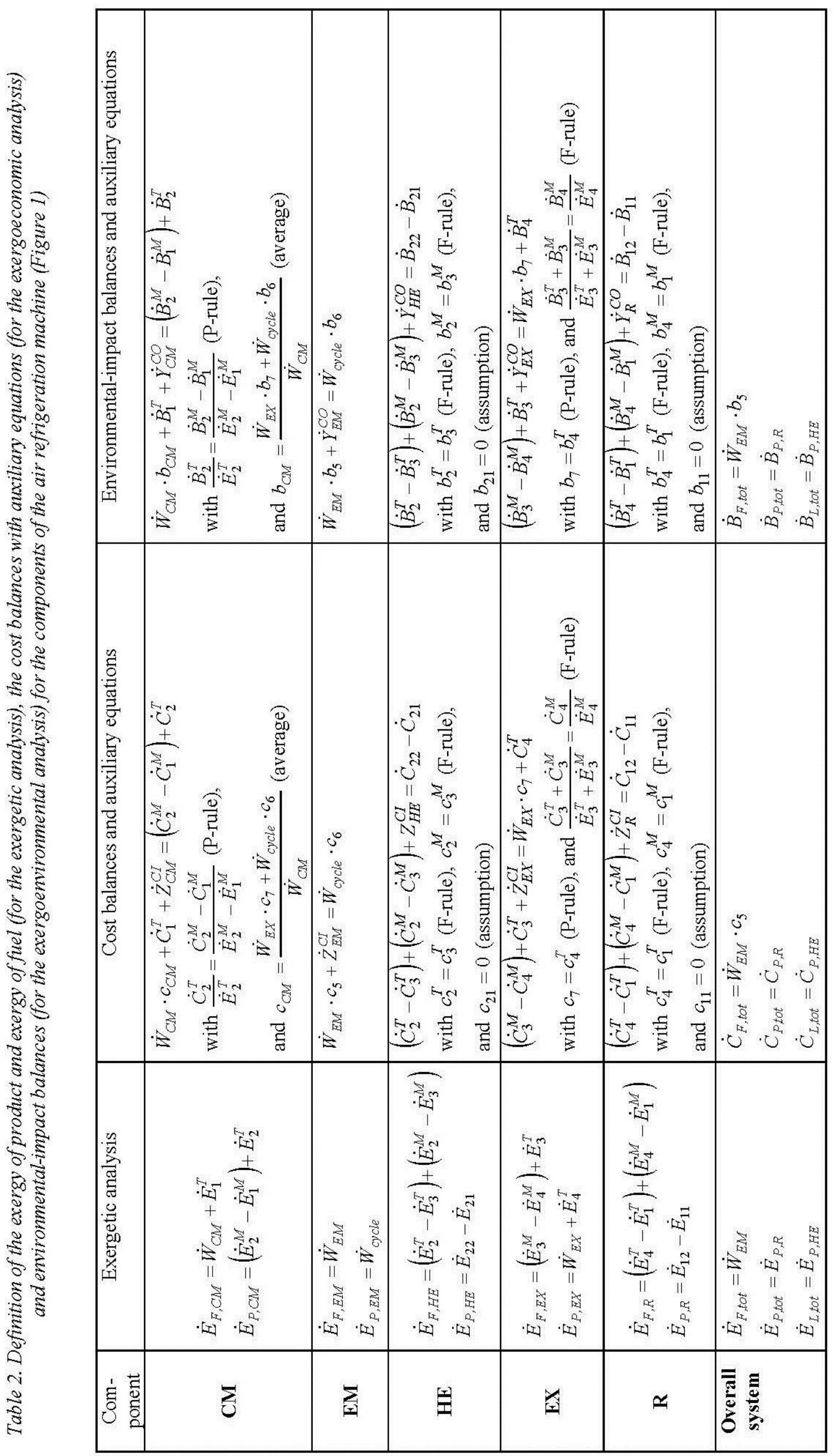


Table 3. Conventional exergetic analysis for the base case of the air refrigeration machine (Figure 1).

\begin{tabular}{|c|c|c|c|c|c|}
\hline Component & $\dot{E}_{F, k}[\mathrm{~kW}]$ & $\dot{E}_{P, k}[\mathrm{~kW}]$ & $\dot{E}_{D, k}[\mathrm{~kW}]$ & $\varepsilon_{k}[\%]$ & $y_{k}[\%]$ \\
\hline CM & 801.20 & 687.90 & 113.30 & 85.9 & 25.3 \\
\hline EM & 447.56 & 402.80 & 44.76 & 90.0 & 10.0 \\
\hline HE & 109.10 & 12.24 & 96.86 & 11.2 & 21.6 \\
\hline $\mathbf{E X}$ & 561.20 & 427.30 & 133.90 & 76.1 & 29.9 \\
\hline $\begin{array}{c}\text { Overall system } \\
\left.\dot{E}_{L, t o t}=12.24 \mathrm{~kW}\right)\end{array}$ & 46.56 & 15.51 & 31.05 & 33.3 & 6.9 \\
\hline
\end{tabular}

Table 4. Values of selected exergoeconomic variables for the air refrigeration machine (base case).

\begin{tabular}{|c|c|c|c|c|c|c|c|}
\hline Component & $\begin{array}{c}\dot{Z}_{k} \\
{[€ / \mathrm{h}]}\end{array}$ & $\begin{array}{c}\dot{C}_{D, k} \\
{[€ / \mathrm{h}]}\end{array}$ & $\begin{array}{c}\dot{Z}_{k}+\dot{C}_{D, k} \\
{[€ / \mathrm{h}]}\end{array}$ & $\begin{array}{c}c_{F, k} \\
{[€ / \mathrm{MJ}]}\end{array}$ & $\begin{array}{c}c_{P, k} \\
{[€ / \mathrm{MJ}]}\end{array}$ & $\begin{array}{c}r_{k} \\
{[\%]}\end{array}$ & $\begin{array}{c}f_{k} \\
{[\%]}\end{array}$ \\
\hline $\mathbf{C M}$ & 2.44 & 39.98 & 42.42 & 0.098 & 0.115 & 17.5 & 5.8 \\
\hline $\mathbf{E M}$ & 0.37 & 6.30 & 6.67 & 0.039 & 0.044 & 11.8 & 5.5 \\
\hline $\mathbf{H E}$ & 1.54 & 40.16 & 41.70 & 0.115 & 1.062 & 821.7 & 3.7 \\
\hline $\mathbf{E X}$ & 2.63 & 55.53 & 58.16 & 0.115 & 0.153 & 32.8 & 4.5 \\
\hline $\mathbf{R}$ & 2.34 & 15.51 & 17.85 & 0.139 & 0.458 & 230.4 & 13.1 \\
\hline $\begin{array}{l}\text { Overall } \\
\text { system }\end{array}$ & $\mathbf{9 . 3 2}$ & $\mathbf{2 1 3 . 2 8}$ & $\mathbf{2 2 2 . 6 0}$ & $\mathbf{0 . 1 5 3}$ & $\mathbf{0 . 4 5 8}$ & $\mathbf{1 9 9 . 3}$ & $\mathbf{4 . 2}$ \\
\hline
\end{tabular}

where $\dot{m}_{\text {cycle }}$ is the mass flow rate of the working fluid (air) through the compressor and expander, $\eta_{C M}$ and $\eta_{E X}$ are the isentropic efficiencies of the compressor and the expander, and $\eta_{C M}^{U N}$ and $\eta_{E X}^{U N}$ are the isentropic efficiencies corresponding to unavoidable exergy destruction for the compressor and the expander (both assumed to be equal to 0.95). According to the concept of unavoidable exergy destruction with a component, the PEC value at unavoidable irreversibilities tends to infinity.

The equations for estimating the PEC for the heat exchanger, and refrigerator are functions of the area of heattransfer surface (assuming that the overall heat-transfer coefficient remains constant). For the electrical motor, PEC depends on the required electric power:

- Heat exchanger

$$
P E C_{H E}=3092\left(A_{H E}\right)^{0.6}
$$

- Refrigerator

$$
P E C_{H E}=3526\left(A_{R}\right)^{0.6}
$$

- Electrical motor

$$
P E C_{E M}=1697\left(\dot{W}_{E M}\right)^{0.4}
$$

The following data were used to calculate the capital investment cost rates: Average cost of money $i_{e f f}=10 \%$; plant economic life $n=15$ years; average general inflation rate $r_{n}=2.5 \%$, and annual number of hours of system operation at full capacity 7000 hours/year.

The cost balances and auxiliary equations for the exergoeconomic model of the air refrigeration machine are given in Table 2. Table 4 shows the data obtained from the exergoeconomic analysis for the Base Case.

\section{LCA}

In this paper for an LCA, an impact analysis method called Eco-indicator 99 (Goedkoop and Spriensma, 2000) has been selected because it considers many environmental aspects and uses average European data. In order to identify the raw materials inlet flows, it is first necessary to perform a sizing of the plant components and to collect information about the weights, main materials, production processes and scrap outputs of all relevant pieces of equipment needed to build the plant. This information is usually not very widely published neither the materials used for each equipment item are given. In this way, only rough calculations of the employed main materials can be conducted. The data collected in publications by Tsatsaronis and Morosuk, 2008; Cabrera, 2010; Morosuk et al., 2001 were generalized in the form of the Equations (17)-(21) and used for estimating the component-related environmental impact that occurs during the construction phase. For the sensitivity analysis we assumed that the relative materials consumption remains unchanged and only different manufactory methods are used, in order to achieve lower irreversibilities within the components.

The generalized equations used for estimating the component-related environmental impact are (The values of component-related environmental impacts are calculated in Points of Eco-indicator 99):

\section{- Compressor (25\% Steel and 75\% Steel Low Alloy)}

$Y_{C M}=0.2457 \cdot \dot{W}_{C M}+15538$

- Expander (25\% Steel and 75\% Steel Low Alloy)

$Y_{E X}=0.2457 \cdot \dot{W}_{E X}+15538$

- Heat exchanger $(100 \%$ Steel $)$

$Y_{H E}=0.703 \cdot A_{H E}+12.03$ 
- Refrigerator (25\% Steel and 75\% Steel Low Alloy)

$Y_{R}=11.2738 \cdot A_{R}+223.9321$

- Electrical motor (40\% Steel, 40\% Steel Low Alloy, 20\% Cupper)

$Y_{E M}=0.129\left(\dot{W}_{E M}\right)^{0.67}$

For these equations, the unit of power $(\dot{W})$ is $\mathrm{kW}$ and the unit of heat -transfer surface $(A)$ is $\mathrm{m}^{2}$.

The environmental impact of electricity is assumed to be $b_{e l}=27 \mathrm{mPts} / \mathrm{kWh}$ (Goedkoop and Spriensma, 2000).

The cost balances and auxiliary equations for the exergoenvironmental model of the air refrigeration machine are given in Table 2. Table 5 shows the data obtained from the exergoenvironmental analysis for the Base Case.

\section{3D Analysis}

Figures 3 and 4 show the results obtained from the sensitivity exergetic, exergoeconomic and exergoenvironmental analyses in the form of 3D diagram. For this analysis we assumed:

- The isentropic efficiency of the compressor is varied between $75 \%$ and $94 \%$,

- The isentropic efficiency of the expander is varied between $75 \%$ and $94 \%$,

- The minimal temperature difference within the heat exchanger is varied between $3 \mathrm{~K}$ and $15 \mathrm{~K}$,

- The minimal temperature difference within the refrigerator is varied between $3 \mathrm{~K}$ and $25 \mathrm{~K}$,

- The efficiency of the electrical motor remains constant.

Figure 3 shows the interdependencies among the variables $\dot{E}_{D, k} / \dot{E}_{P, k}, \dot{Z}_{k}^{C I} / \dot{E}_{P, k}$ and $\dot{Y}_{k}^{C O} / \dot{E}_{P, k}$, while Figure 4 shows the interdependences among the variables $\dot{E}_{D, k} / \dot{E}_{P, k}, \dot{C}_{D, k} / \dot{E}_{P, k}$ (cost of the exergy destruction), and $\dot{B}_{D, k} / \dot{E}_{P, k}$ (environmental impact associated with the exergy destruction). Figure 5 summarizes the data from Figures 3 and 5, i.e. shows the interdependencies among the variables $\dot{E}_{D, k} / \dot{E}_{P, k}, \quad\left(\dot{C}_{D, k}+\dot{Z}_{k}\right) / \dot{E}_{P, k} \quad$ (total cost associated with the $k$ th component), and $\left(\dot{B}_{D, k}+\dot{Y}_{k}\right) / \dot{E}_{P, k}$ (total environmental impact associated with the $k$ th component).

Figure 6 demonstrates the interdependencies among total exergy destruction, cost and environmental impact of the total product. For Figure 6 we selected only the data that are lower than in the base case. This gives us an opportunity to discuss the improvement of the overall system from the thermodynamic, economic and environmental points of view.

\section{Results and discussions}

Table 3 shows the results of the conventional exergetic analysis of the air refrigeration machine. Based on the values of $\dot{E}_{D, k}$ we can conclude that the expander and the compressor are the most important components from the thermodynamic viewpoint. The improvement of the evaporator cannot significantly affect the improvement of the air refrigeration machine.

From the point of view of the advanced exergetic analysis (theory and results have been reported by Morosuk and Tsatsaronis, 2011a,b), the priority for the thermodynamic improvement of the air refrigeration machine is: Expander, refrigerator, compressor, and heat exchanger. This priority was established by considering for each component the sum of (a) the avoidable endogenous exergy destruction, and (b) the total avoidable exogenous exergy destruction caused by the component being considered within the remaining components.

From the economic point of view (values of $\dot{Z}_{k}$ ), the turbomachines and the refrigerator are the most expensive components. From the exergoeconomic point of view (sum of $\dot{Z}_{k}+\dot{C}_{D, k}$ ), the same components are very important. The cost of the final product (cold) can be reduced by reducing the cost of the exergy destruction $\left(\dot{C}_{D, k}\right)$ within all components. This can be achieved by decreasing the exergy destruction within the components, because of the relationship $\dot{C}_{D, k}=c_{F, k} \cdot \dot{E}_{D, k}$. For this refrigeration machine we have a not very common situation, where thermodynamic and cost improvements are obtained by the same changes.

From the LCA analysis (values of $\dot{Y}_{k}$ ), we have conclusions similar to the conclusions obtained from the economic analysis: The turbomachines and the refrigerator are the most "expensive" components from the environmental point of view. Results of the exergoenvironmental analysis shows (Table 5) that in the sum $\left(\dot{Y}_{k}+\dot{B}_{D, k}\right)$ the most important contributor is $\dot{B}_{D, k}$ (environmental impact associated with the exergy destruction). In this way, we have again the situation, where the thermodynamic and environmental improvements are obtained by the same changes (this situation is, however common in energy-conversion systems).

Table 5. Values of selected exergoenvironmental variables for the base case of the air refrigeration machine.

\begin{tabular}{|c|r|r|r|r|r|r|r|}
\hline Component & $\begin{array}{c}\dot{Y}_{k} \\
{[\mathrm{mPts} / \mathrm{h}]}\end{array}$ & $\begin{array}{c}\dot{B}_{D, k} \\
{[\mathrm{mPts} / \mathrm{h}]}\end{array}$ & $\begin{array}{c}\dot{Y}_{k}+\dot{B}_{D, k} \\
{[\mathrm{mPts} / \mathrm{h}]}\end{array}$ & $\begin{array}{c}b_{F, k} \\
{[\mathrm{mPts} / \mathrm{MJ}]}\end{array}$ & $\begin{array}{c}b_{P, k} \\
{[\mathrm{mPts} / \mathrm{MJ}]}\end{array}$ & $\begin{array}{c}r_{k} \\
{[\%]}\end{array}$ & $\begin{array}{c}f_{k} \\
{[\%]}\end{array}$ \\
\hline $\mathbf{C M}$ & 0.150 & 7134 & 7134 & 17.5 & 20.4 & 16.5 & 0.002 \\
\hline EM & 0.028 & 1209 & 1209 & 7.5 & 8.3 & 11.1 & 0.002 \\
\hline $\mathbf{H E}$ & 0.002 & 7105 & 7105 & 20.4 & 181.6 & 791.3 & $<0.001$ \\
\hline $\mathbf{E X}$ & 0.149 & 9824 & 9824 & 20.4 & 26.8 & 31.3 & 0.002 \\
\hline $\mathbf{R}$ & 0.043 & 2723 & 2723 & 24.4 & 73.1 & 200.2 & 0.002 \\
\hline $\begin{array}{c}\text { Overall } \\
\text { system }\end{array}$ & 0.390 & 11337 & 11337 & 7.5 & 251.4 & 3252 & 0.003 \\
\hline
\end{tabular}



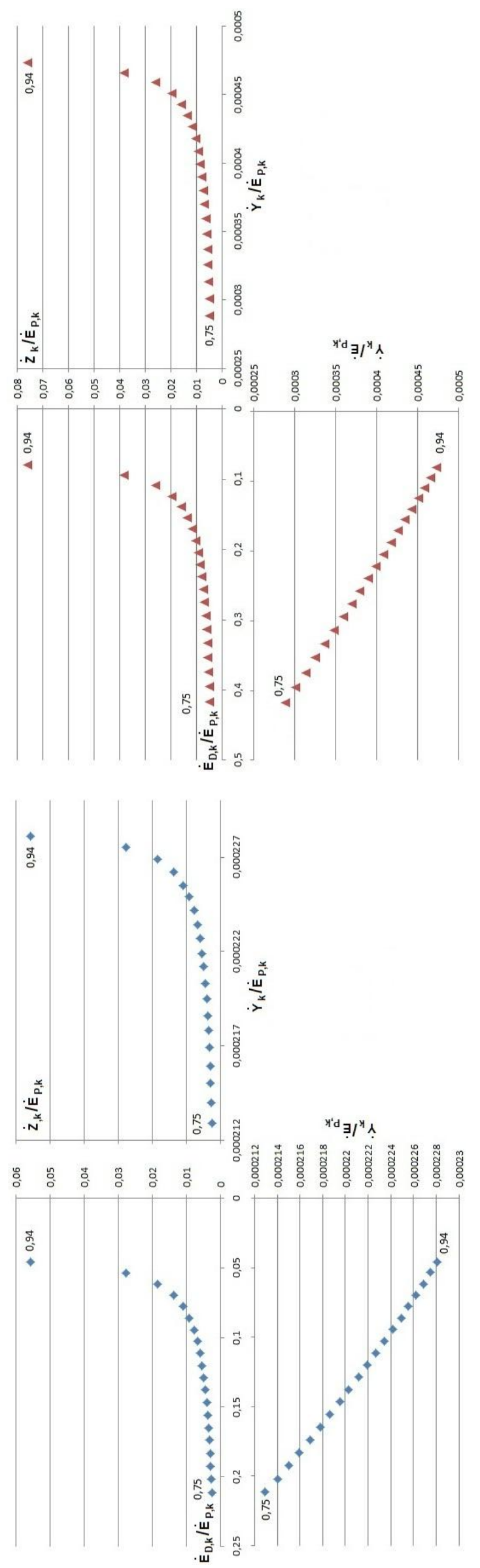
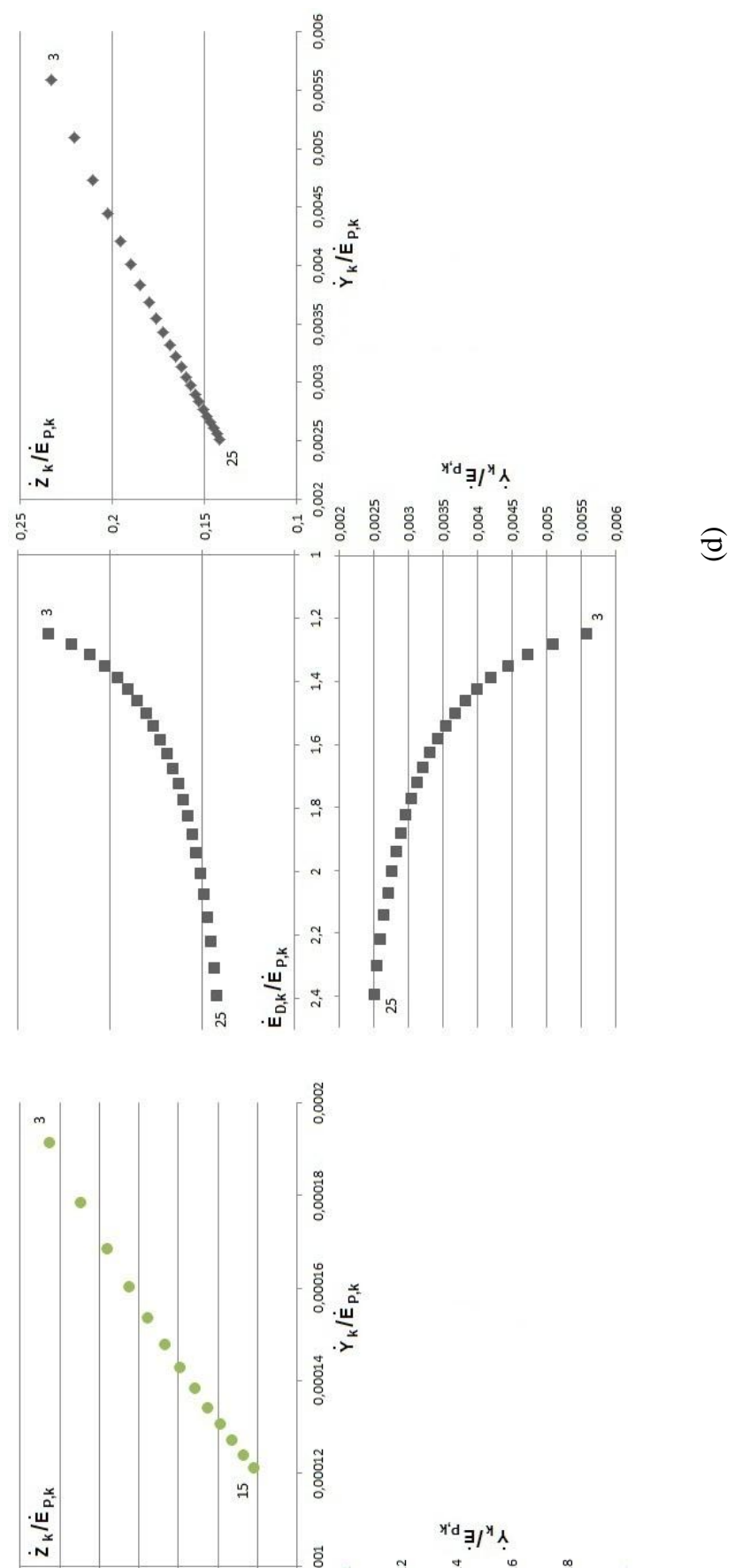

త

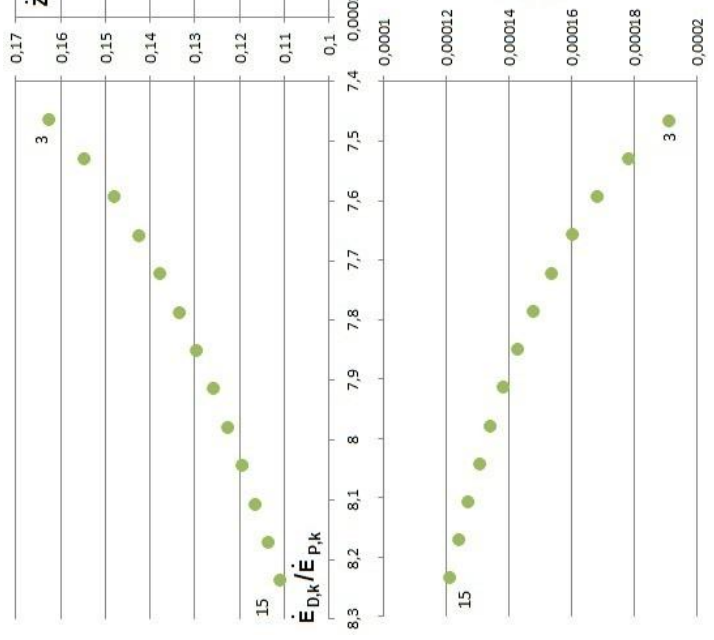

Figure 3. Relationships among capital investment, construction-of-component-related environmental impact and exergy destruction for the $k$ th component of the air refrigeration machine:(a) compressor; $(b)$ expander; (c) heat exchanger, and (d) refrigerator. 


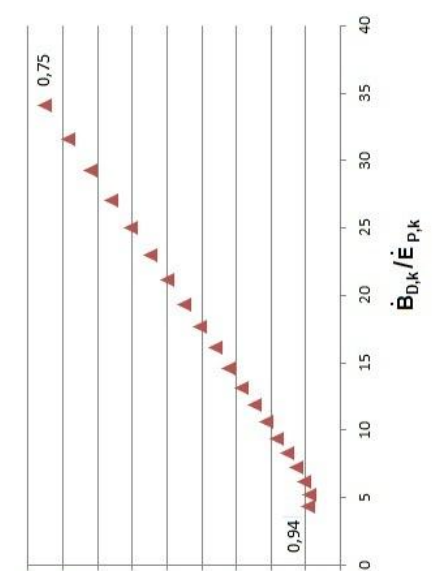

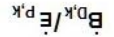

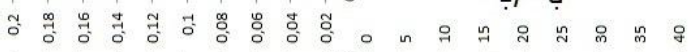
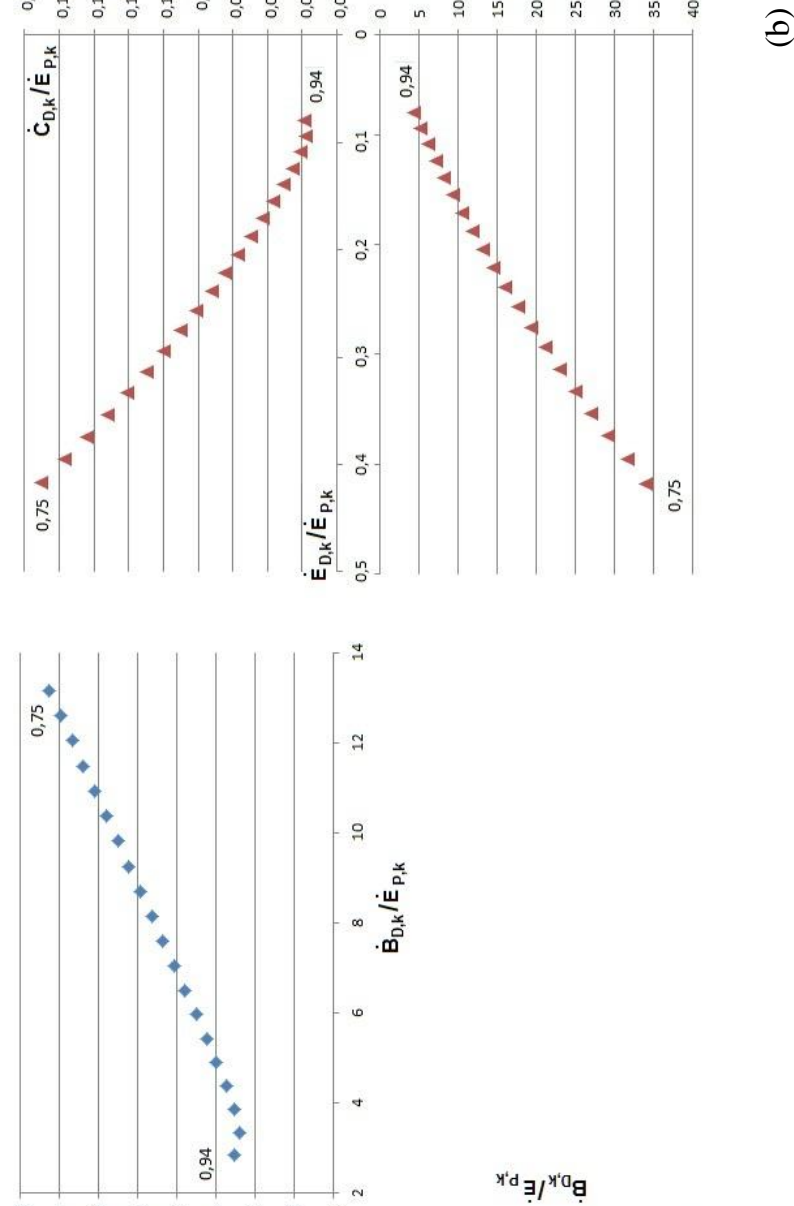

:

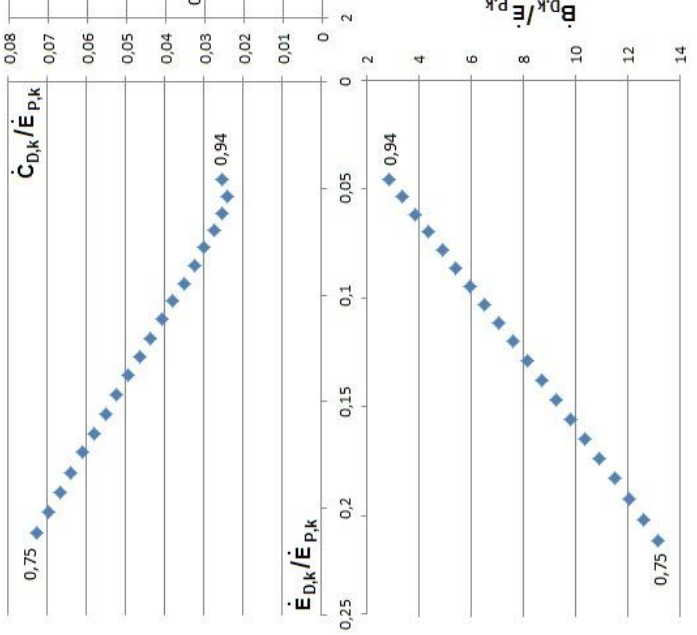

$\hat{e}$
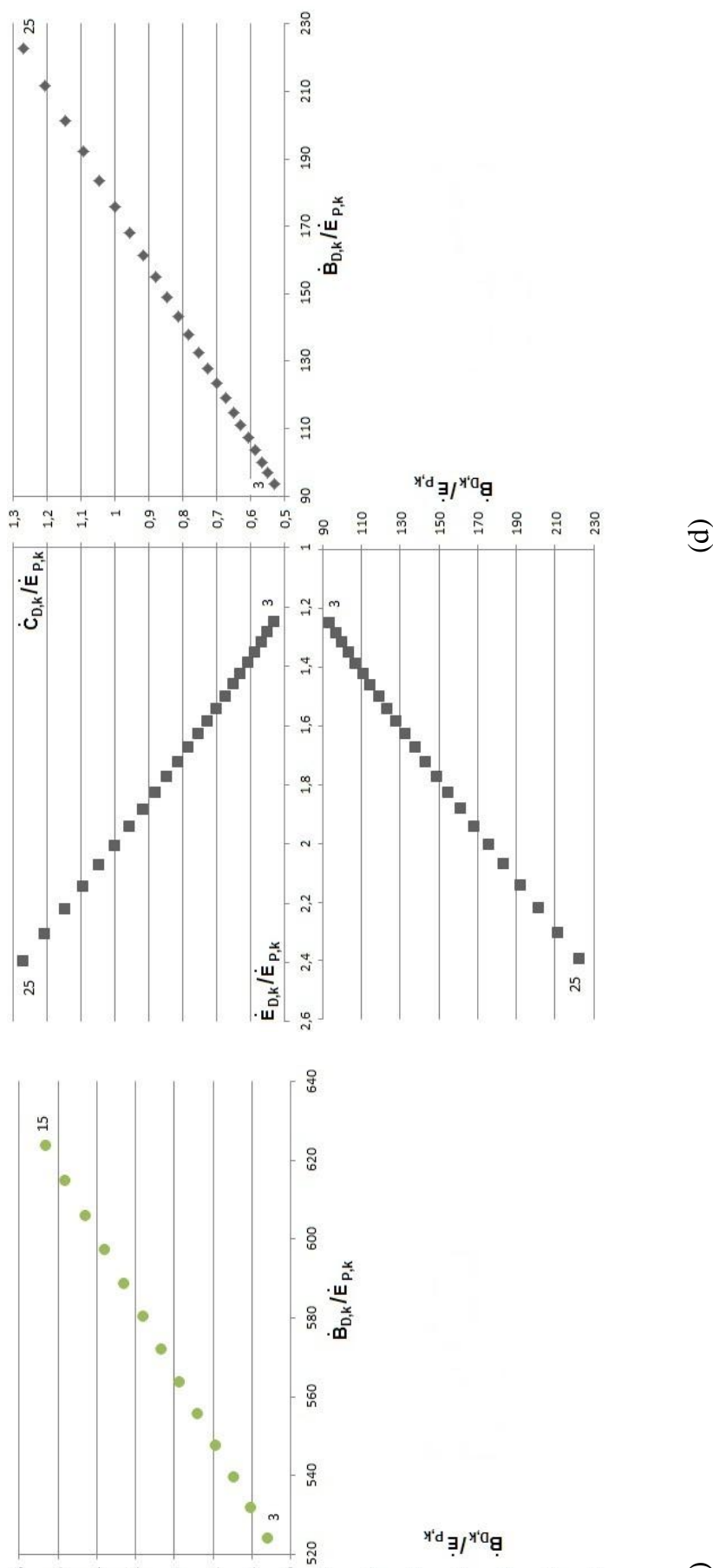

$\mathrm{x}^{\mathrm{d} d} \exists / /^{\mathrm{y}^{\mathrm{d}} \mathrm{a}} \mathrm{g}$

Ð

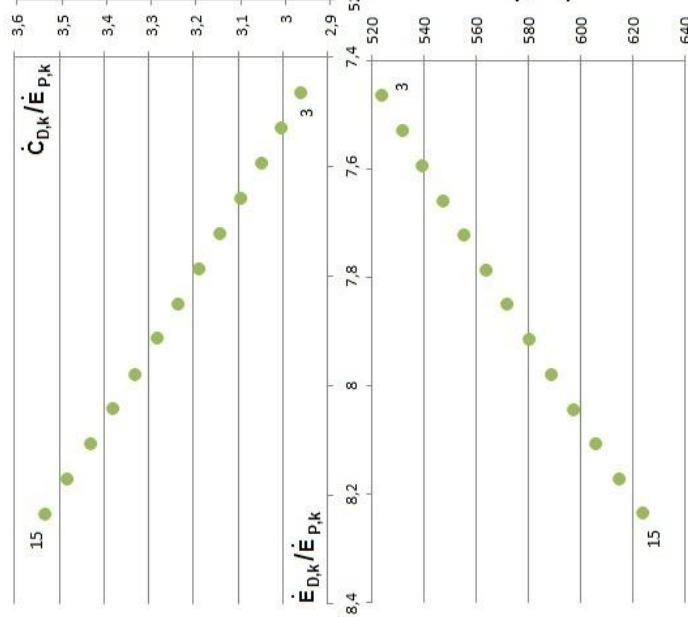

Figure 4. Relationships among cost of the exergy destruction, environmental impact associated with the exergy destruction and exergy destruction for the $k$ th component of the air refrigeration machine:(a) compressor; (b) expander; (c) heat exchanger, and (d) refrigerator. 


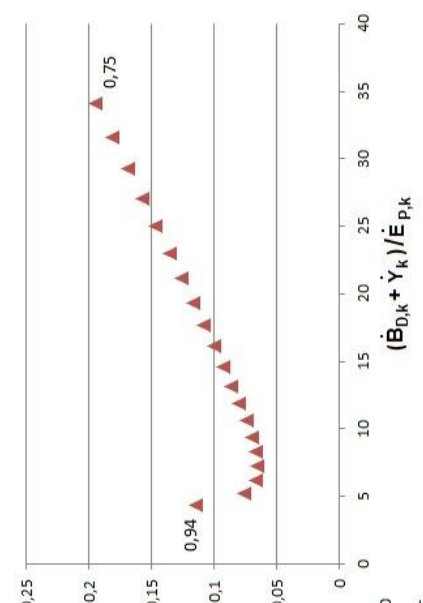

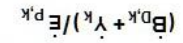

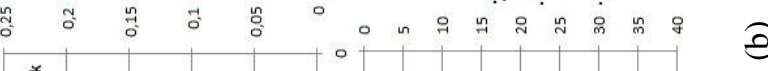
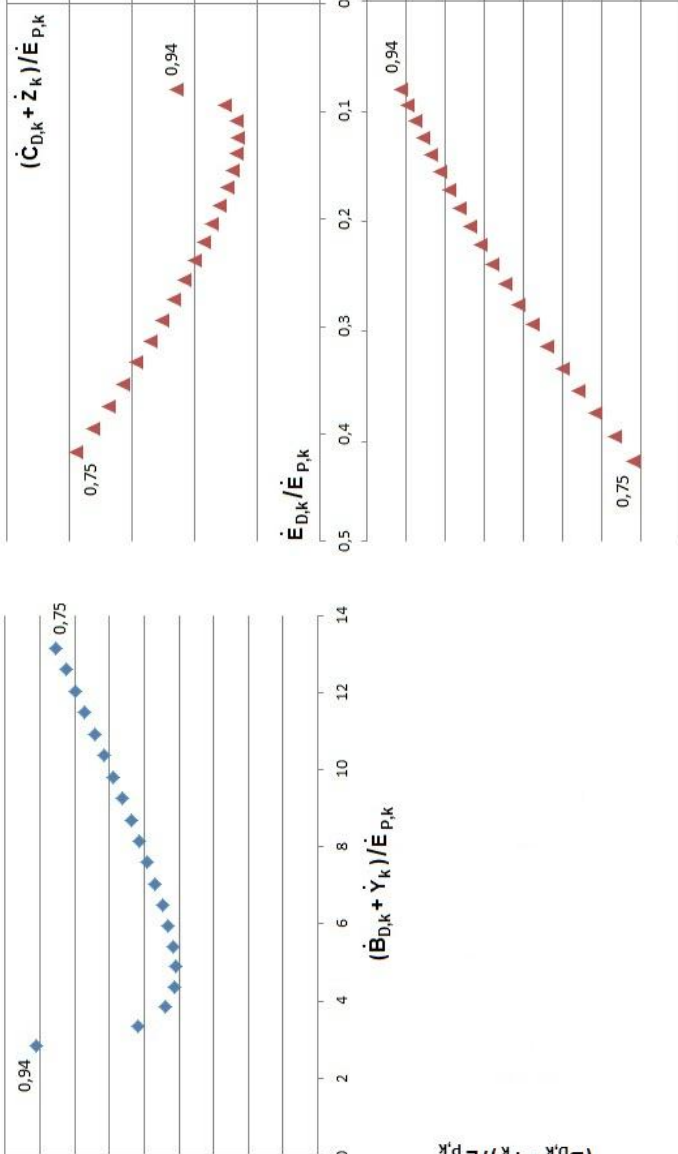

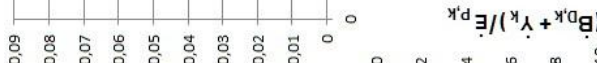

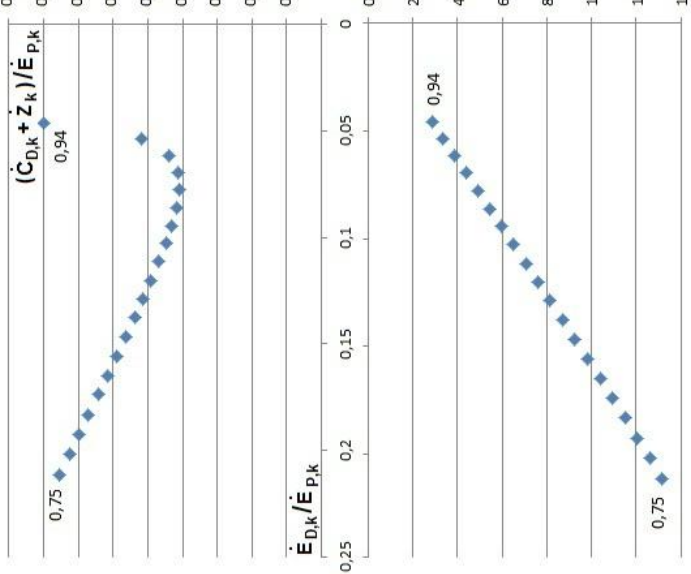

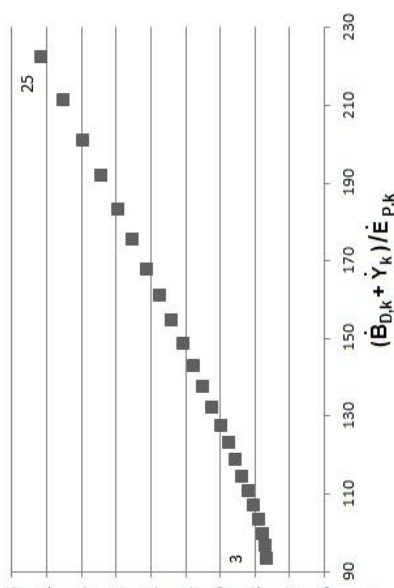

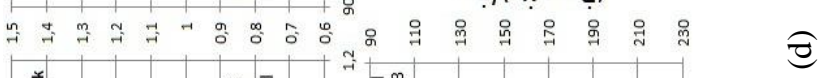
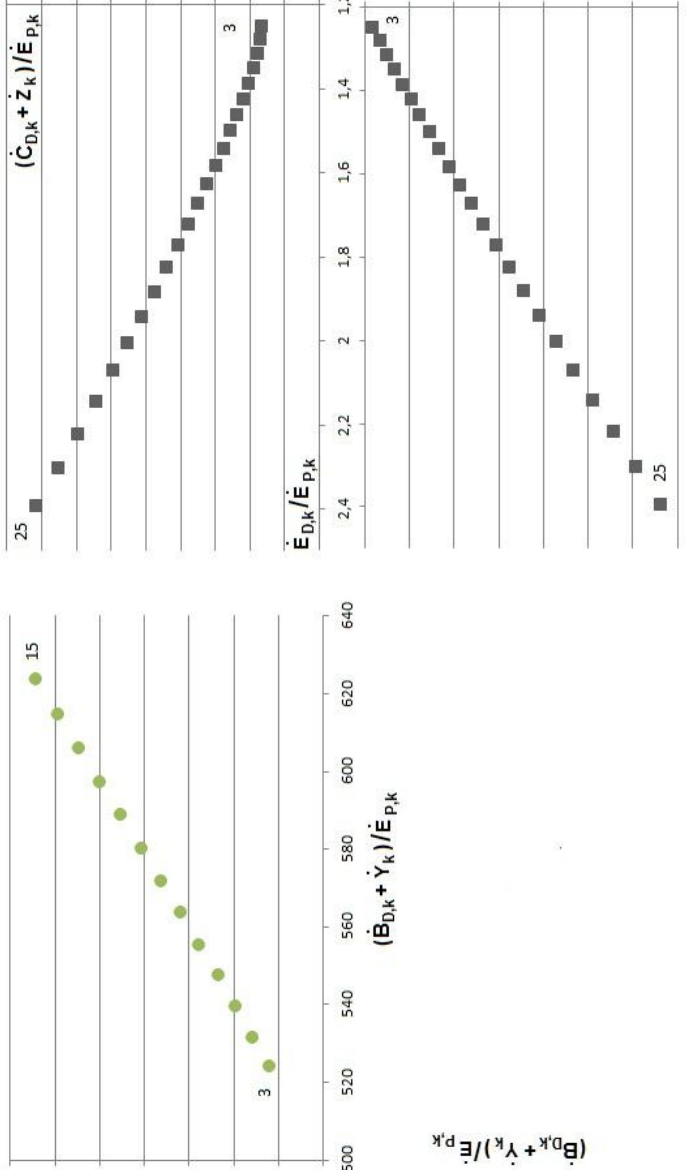

త్ర
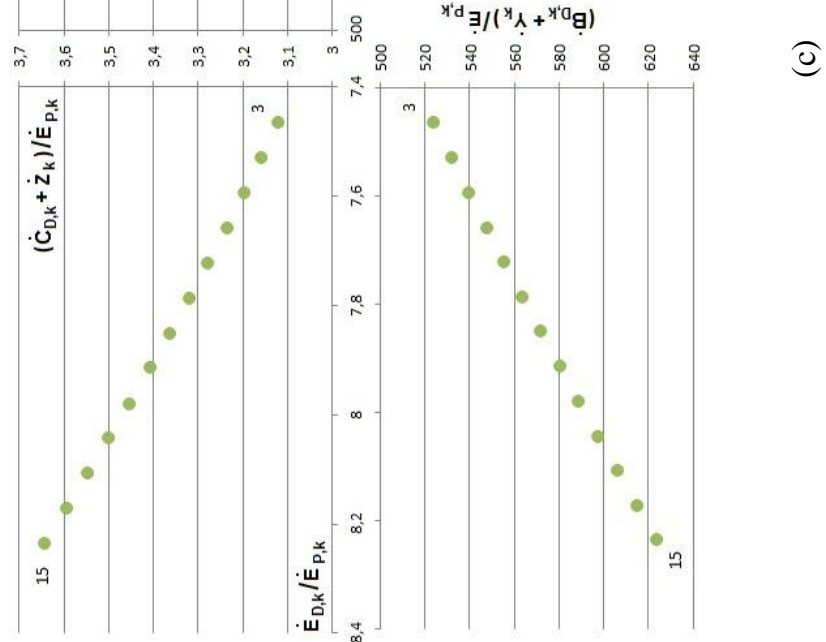

Figure 5. Relationships among total cost, total environmental impact and exergy destruction for the $k$ th component of the air refrigeration machine: (a) compressor; (b) expander; (c) heat exchanger, and (d) refrigerator. 


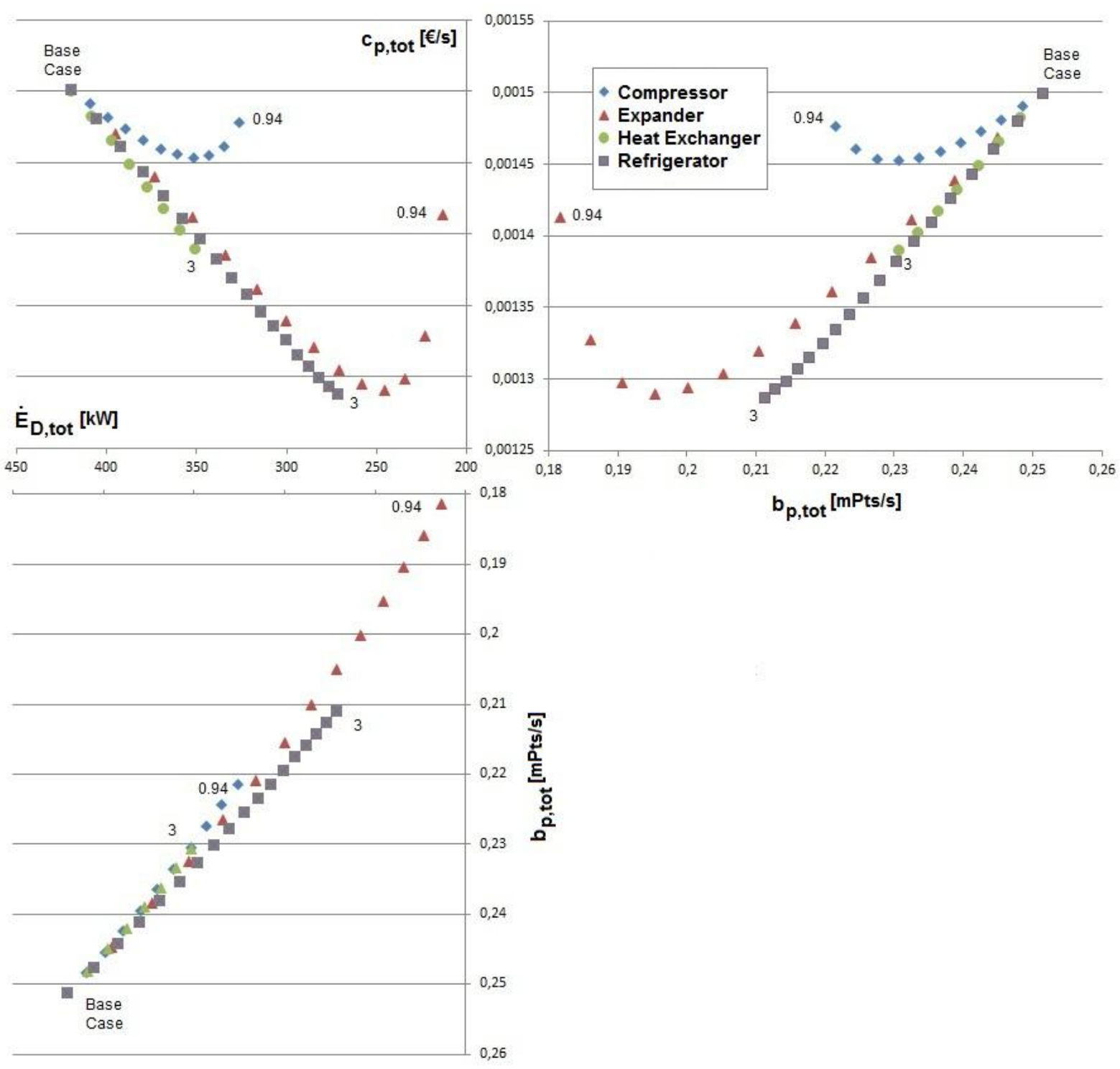

Figure 6. Relationships among cost and environmental impact of the total product of the air refrigeration machine and total exergy destruction.

The data obtained from the sensitivity analysis (Figure 3) show that the character of the three curves $\left(\dot{E}_{D, k} / \dot{E}_{P, k}\right.$, $\dot{Z}_{k}^{C I} / \dot{E}_{P, k}$ and $\left.\dot{Y}_{k}^{C O} / \dot{E}_{P, k}\right)$ corresponds to the general case (a) in Figure 1, but with different shapes. In this way, we have the situation where lower values of $\dot{E}_{D, k} / \dot{E}_{P, k}$ simultaneously correspond to lower values of $\dot{Z}_{k}^{C I} / \dot{E}_{P, k}$ and of $\dot{Y}_{k}^{C O} / \dot{E}_{P, k}$.

Figure 4 shows that the interdependencies between $\dot{E}_{D, k} / \dot{E}_{P, k}$ and $\dot{C}_{D, k} / \dot{E}_{P, k}$ as well as between $\dot{E}_{D, k} / \dot{E}_{P, k}$ and $\dot{B}_{D, k} / \dot{E}_{P, k}$ have opposite behaviour. This provides the opportunity that the total cost associated with the component $\left(\dot{C}_{D, k}+\dot{Z}_{k}\right) / \dot{E}_{P, k}$ and the total environmental impact associated with the component could go through a minimum value within the range of parameters variation used for the sensitivity analysis. Figure 5 demonstrates that this case exists only for the exergoeconomic variables of the turbomachines. From Table 5 we already know that variations in the value of $\dot{Y}_{k}$ cannot affect significantly the $\operatorname{sum}\left(\dot{B}_{D, k}+\dot{Y}_{k}\right)$.

In order to estimate the effect of irreversibilities within the components to the overall thermodynamic, economic and environmental characteristics of the air refrigeration machine, the following three characteristics were analyzed simultaneously: Total exergy destruction $\left(\dot{E}_{D, t o t}\right)$, specific $\operatorname{cost}\left(c_{P, t o t}\right)$ and specific environmental impact $\left(b_{P, t o t}\right)$ of the product. For Figure 6 we selected the data that correspond to the base case (Tables 3, 4 and 5) or lower values that demonstrate the possibility for improving the overall system. The following conclusions we can obtain through the detailed analysis of the data shown in Figure 6:

- For the air refrigeration machine, the thermodynamic improvement of any of the components leads to a decrease in the values of $\dot{E}_{D, t o t}$ and $b_{P, t o t}$, i.e. to an improvement in the total plant. 
- For the turbomachines the function $c_{P, t o t}$ has a minimum, therefore the same value of $c_{P, t o t}$ corresponds to the compressor and the expander with different efficiencies.

- Within the range of $\dot{E}_{D, t o t}=419.9 \mathrm{~kW}$ (base case) and $\dot{E}_{D, t o t} \approx 370 \mathrm{~kW}$, the contribution of all components in decreasing the value of $b_{P, t o t}$ is quite similar, whereas for $\dot{E}_{D, t o t}<370 \mathrm{~kW}$ we can see some differences. In the range $\dot{E}_{D, t o t}=419.9 \mathrm{~kW}$ to $370 \mathrm{~kW}$ the contribution of all components (with the exception of compressor) in decreasing the value of $c_{P, t o t}$ is also quite similar. In this range of $\dot{E}_{D, t o t}$ values, the three components (expander, heat exchanger and refrigerator) can lead to similar improvements of the overall system.

- If the total exergy destruction is lower than approximately $370 \mathrm{~kW}$, then only the expander and refrigerator can contribute to improving the air refrigeration machine. Note that improving the expander has a higher effect on the thermodynamic, economic and LCA characteristics of the overall air refrigeration machine than improving the compressor.

- Quarter III in Figure 6 clearly demonstrates that the expander and the refrigerator have a higher potential for simultaneously decreasing cost and environmental impact of the overall product.

The last conclusion obtained from the 3D sensitivity analysis fully confirms the conclusions obtained from the advanced exergetic analysis conducted for the same refrigeration machine (Morosuk and Tsatsaronis, 2011a,b).

\section{Conclusions}

A relatively simple energy-conversion system (without a chemical reaction) was used in this paper to study the interdependencies among costs, environmental impacts and thermodynamic inefficiencies. The results demonstrate that in an air refrigeration machine, improvements in efficiency result, in general, to decreases in both costs and environmental impacts. The detailed sensitivity analysis fully confirms findings obtained through advanced exergybased analyses. The analysis presented here suggests ways for improving an energy-conversion system simultaneously from a thermodynamic, economic and ecological viewpoint.

\section{Nomenclature}

$B$ environmental impact associated with an exergy stream [Points]

$b$ environmental impact per unit of exergy [Points/J]

$C$ cost associated with an exergy stream [€]

$c$ cost per unit of exergy $[€ / J]$

$E$ exergy [J]

$e \quad$ specific exergy $[\mathrm{J} / \mathrm{kg}]$

$f$ exergoeconomic factor [-]

$k \quad k$ th component [-]

$m$ mass [kg]

$p$ pressure $[\mathrm{Pa}]$

$r$ relative cost difference [\%]

$T$ temperature [K]

$Y$ construction-of-component-related environmental impact [Points] $y$ exergy destruction ratio [-]

$Z$ cost associated with investment expenditures [€]

Greek symbols

$\varepsilon \quad$ exergetic efficiency [\%]

$\eta \quad$ isentropic efficiency [\%]

\section{Subscripts}

$b$ refers to environmental impact

$D$ refers to exergy destruction

$F$ fuel

$P$ product

tot refers to the total system

$Y$ refers to construction-of-component-related environmental impact

$Z$ refers to investment costs

\section{References}

Bejan A., Tsatsaronis G., Moran M., 1996, Thermal Design and Optimization, Wiley, New York.

Boyano A., Blanco-Marigorta A.M., Morosuk T., Tsatsaronis G., 2011, Exergoenvironmental analysis of a steam methane reforming process for hydrogen production. Energy Int. J., Vol.36 (4), pp. 2202-2214.

Cabrera Cabrera M. Exergoenvironmental Analysis of Oxyfuel-based Combined-Cycle Power Plants including $\mathrm{CO}_{2}$ Capture, Master Thesis, Technische Universität Berlin, 2010.

Goedkoop M., Spriensma R., 2000, The Eco-indicator 99: A damage oriented method for Life Cycle Impact Assessment. Methodology Report. Amersfoort, Netherlands, (http: llwww.pre.nl).

Kakac S., Liu H., 1998, Heat exchangers: Selection, rating, and thermal design. CRC Press LLC.

Lazzaretto A., Tsatsaronis G., 2006, SPECO: A systematic and general methodology for calculating efficiencies and costs in thermal systems, Energy - The International Journal, Vol. 31, pp. 1257-1289.

Meyer L., Tsatsaronis G., Buchgeister J. and Schebek L., 2009, Exergoenvironmental Analysis for Evaluation of the Environmental Impact of Energy Conversion Systems, Energy Int. J., Vol. 34, 2009, pp. 75-89.

Morosuk T., Tsatsaronis G., 2005, Graphical models for splitting physical exergy. Proceedings of ECOS-2005 "Shaping our future energy systems", Kjelstrup, S., Hustad, J.E., Gundersen, T., Rosjorde, A. and Tsatsaronis, G., eds., 1, pp. 377-384.

Morosuk T., Tsatsaronis G., 2011, Advanced exergoeconomic analysis of a refrigeration machine: Part 1. Methodology and first evaluation. Proceedings of the ASME 2011 International Mechanical Engineering Congress \& Exposition (IMECE2011), November 11-17, 2011, Denver, Colorado, USA, CDROM, file IMECE2011-62688.

Morosuk T., Tsatsaronis G., 2011, Advanced exergoeconomic analysis of a refrigeration machine: Part 2. Improvement. Proceedings of the ASME 2011 International Mechanical Engineering Congress \& Exposition (IMECE2011), November 11-17, 2011, 
Denver, Colorado, USA, CD-ROM, file IMECE201162689.

Morosuk T., Tsatsaronis G., Boyano A., Gantiva C., 2012, Advanced exergy-based analyses applied to a system including LNG regasification and electricity generation. International Journal of Energy and Environmental Engineering (A Springer Open Journal http://www.journal-ijeee.com/content/3/1/1), 3:1, 9 p.

Tsatsaronis G., 1984, Combination of Exergetic and Economic Analysis in Energy-Conversion Processes. In: Energy Economics and Management in Industry, Proceedings of the European Congress, Algarve,
Portugal, April 2-5, 1984, England, Oxford: Pergamon Press, Vol. 1, pp. 151-157.

Tsatsaronis G., 2008, Recent developments in exergy analysis and exergoeconomics, Int. J. Exergy, Vol. 5, Nos. 5/6, pp.489-499.

Tsatsaronis G., Morosuk T., 2008, A general exergy-based method for combining a cost analysis with an environmental impact analysis. Proceedings of the ASME International Mechanical Engineering Congress and Exposition, Boston, USA, 2008, files IMECE200867218 and IMECE2008-67219. 